\title{
Simulation of the Rat Intestinal Ecosystem using a Two-stage Continuous Culture System
}

\author{
By B. G. VEILLEUX* AND I. ROWLAND \\ The British Industrial Biological Research Association, Woodmansterne Road, Carshalton, \\ Surrey SM5 4DS
}

(Received 24 March 1980; revised 5 August 1980)

To investigate the ecological mechanisms governing the community structure of the gut microbial ecosystem, we have attempted to simulate the rat gut ecosystem in vitro using a two-stage continuous culture. Extensive sampling of the rat hindgut has established a set of criteria with which the in vitro system may be compared. This paper discusses one of the criteria, the community composition and structure in vivo and in vitro. The experiments indicated that a gut microbial ecosystem could be satisfactorily mimicked in vitro. This was achieved using a two-stage continuous culture employing differential selection of species between the two stages on the basis of $\mathrm{pH}$ differences combined with cell recycling between stages.

\section{INTRODUCTION}

The indigenous microflora of the mammalian alimentary canal is part of a complex ecosystem influenced by biotic and abiotic factors. Gastrointestinal ecosystems are complex with a high degree of interaction among the different components, resulting in a sustained capacity for self-regulation and homeostasis (Dubos et al., 1965; Savage, 1977; Fretner, 1974).

The gut microflora significantly influences the anatomical, physiological and immunological characteristics of the animal (Gorden \& Pesti, 1972; Berg, 1978). It is important, therefore, to understand the ecological mechanisms governing the interactions between the bacteria and the host and amongst the bacteria themselves. Although the relationships between a few gut microbes have been studied in continuous culture (Fretner \& Aranki, 1973 ) or by specifically colonizing germ-free rodents (Berg, 1978), the interspecific mechanisms observed in such simple systems may not be relevant in the more complicated environment of the normal gut (Fretner, 1974). This is particularly true if the intensity of interaction between species is dependent upon the existing community structure (Neill, 1974).

In order to study the mechanisms maintaining the structure of the gut ecosystem it is necessary to manipulate various components of the environment independently and observe the effects of such perturbations on the community composition. Many technical difficulties hinder such investigations in vivo and the lack of environmental constancy and control obscures interpretation of community perturbation experiments.

Although continuous culture systems have been used extensively to model the rumen ecosystem, this technique has been largely neglected in the cultivation of other mammalian gut microfloras (Zubreycki \& Spaulding, 1954; Fretner \& Aranki, 1973). This paper describes attempts to simulate the rat hindgut ecosystem by means of a continuous-flow culture system which may be considered roughly analogous to the natural system. To simplify the environment of the in vitro system, initial consideration was given only to the effects of $\mathrm{pH}$ and the hydraulic regime on the microflora at a fixed temperature, medium 
composition, agitation rate and anaerobic gas composition. Maintenance of the gut ecosystem over an extended period in an environmentally defined growth system could facilitate a study of the interactions between gut micro-organisms, provided the model ecosystem behaved in a similar fashion to the gut. In order to ascertain the similarity between the in vitro and in vivo ecosystems, the following criteria are likely to be important: species diversity; numerical abundance of micro-organisms; metabolic activity of the microflora; ability to metabolize xenobiotic compounds; the response of the microflora to biotic and abiotic perturbations of the environment.

This paper reports comparisons between the in vivo and in vitro ecosystems on the basis of the relative proportions of the main bacterial groups and their species composition at steady-state conditions.

\section{METHODS}

Rats. For the in vivo study, two strains of male rats (Wistar and Sprague Dawley) weighing approximately 150 to $200 \mathrm{~g}$ each were obtained from Charles River (Margate, Kent). They were also sources of inocula for the continuous cultures.

Culture sy'stem and conditions. The medium used in the continuous culture experiments contained, per litre distilled water, $1.5 \mathrm{~g}$ yeast extract (Oxoid), $5 \mathrm{~g}$ Lab-Lemco powder (Oxoid), $5 \mathrm{~g}$ peptone (Oxoid), $0.5 \mathrm{~g}$ soluble starch, $2.5 \mathrm{~g}$ D-glucose, $0.5 \mathrm{~g}$ cysteine. $\mathrm{HCl}, 1.5 \mathrm{~g}$ sodium acetate, $2.5 \mathrm{~g} \mathrm{NaCl}, 4 \mathrm{ml} 0.025 \%(\mathrm{w} / \mathrm{v}$ ) resazurin solution, $10 \mathrm{ml}$ haemin-vitamin $\mathrm{K}$ solution (Holdeman \& Moore, 1975) and $20 \mathrm{ml}$ salts solution lcontaining, per litre distilled water, $0.2 \mathrm{~g} \mathrm{CaCl}_{2}$ (anhydrous), $0.2 \mathrm{~g} \mathrm{MgSO}_{4} .7 \mathrm{H}_{2} \mathrm{O}, 1.0 \mathrm{~g} \mathrm{~K}_{2} \mathrm{HPO}_{4}, 10.0 \mathrm{~g} \mathrm{NaHCO}_{3}$ and $2.0 \mathrm{~g}$ $\mathrm{NaCl}$. The medium was reduced prior to use by the methods of Holdeman \& Moore (1975).

The continuous culture systems were modular type series 500 fermenters (L. H. Engineering, Stoke Poges, Slough, Bucks.) with a culture volume of $600 \mathrm{ml}$. The cultures were agitated at $500 \mathrm{rev} . \mathrm{min}^{-1}$, the temperature was controlled at $37^{\circ} \mathrm{C}$ and the $\mathrm{pH}$ was controlled as described. To maintain anaerobic conditions the cultures were continuously flushed at a rate of $0.5 \mathrm{I} \mathrm{min}^{-1}$ with a humidified mixture of $3 \%(\mathrm{v} / \mathrm{v}) \mathrm{H}_{2}, 10 \%(\mathrm{v} / \mathrm{v}) \mathrm{CO}_{2}$ and $87 \%$ $(\mathrm{v} / \mathrm{v}) \mathrm{N}_{2}$ passed through a catalytic deoxygenator (Deoxo; Engelhard Ltd, Cinderford, Glos.). The medium reservoir was held under the anaerobic gas mixture and agitated to ensure a homogenous distribution of the components. Black butyl rubber tubing was used throughout the system. The medium was pumped continuously by MHRE 7 flow inducers (Watson Marlow, Falmouth, Cornwall). Two-stage cultures were connected in simple series with sterile medium being added to the first stage. Where indicated, cultures were operated with cell recycling. accomplished by transferring part of the culture volume of the second stage to the first with a MHRE 7 flow inducer, using $1 \mathrm{~mm}$ narrow-bore black butyl rubber tubing.

Rat faecal pellets were collected as they passed from the anus and placed immediately in pre-reduced Reinforced Clostridial Medium (RCM, Oxoid) under a stream of $\mathrm{O}_{2}$-free $\mathrm{N}_{2}$. The pellets were homogenized and allowed to settle for $5 \mathrm{~min}$; the supernatant was used either for in vivo sampling or as the culture inoculum. The cultures were grown under batch conditions for $12 \mathrm{~h}$ before starting the flow of fresh medium.

Bacteriological methods. The organisms were grouped using the selective media outlined in Table 1. Petri dishes were inoculated using the procedure of Barnes et al. (1978). Serial 10-fold dilutions were made in pre-reduced RCM broth under $\mathrm{O}_{2}$-free $\mathrm{N}_{2}$ in sealed bottles and $0.1 \mathrm{ml}$ of the appropriate dilution (Table 1), chosen to give 50 to 150 colonies per plate, was spread on the agar surface on the open bench. The colony counts were determined in triplicate for each dilution. For anaerobic incubation, the Petri dishes were placed in anaerobic jars (Baird \& Tatlock. Romford, Essex) immediately after inoculation and flushed with $\mathrm{O}_{2}$-free $\mathrm{N}_{2}$. The anaerobic conditions were maintained with the GasPak system (Becton Dickinson, Wembley, Middx) at $37^{\circ} \mathrm{C}$. The efficiency of anaerobe recovery by open bench inoculation was determined by comparing with direct microscopic counts, using a Neubauer counting chamber and a phase contrast microscope. and with the viable count of anaerobes on RCMblood agar, using strict anaerobic techniques (roll tubes) (Hungate. 1969) with the V.P.I. Anaerobic Culture System (Bellco. Vineland, U.S.A.). The recovery of enterobacteria and streptococci on the selective media (MacConkey and Azide Blood Agars. respectively) was estimated by comparison with their recovery on nonselective, aerobically incubated RCM-blood agar.

Wali growth was observed in the second-stage vessel of the two-stage systems. To determine its species composition, the growth was removed using a sterile $\mathrm{N}_{2}$-filled Pasteur pipette, washed four times in reduced RCM broth, homogenized and then plated on selective media as described above.

The species were identified by colony morphology, Gram's stain and by the API system for micro-organism identification (API Laboratory Products, Farnborough, Hants.). The API system provides a rapid and reliable means of routine species identification using standardized sets of biochemical tests (Dolezil \& Kirsop, 1977). 
Table 1. Selective agars used for the initial identification of micro-organisms from faecal and continuous culture samples

The in vivo and in vitro dilutions refer to faecal and continuous culture (two-stage) samples, respectively. The limiting numerical density for detection of a rare species in a sample was one colony per three plates or about ( $3 /$ dilution) cells per $\mathrm{ml}$ or per $\mathrm{g}$ faeces.

\section{Bacterial group}

Staphylococci

Enterobacteria

Lactobacilli

Streptococci

Total anaerobes

Total aerobes

Veillonellae

Clostridia

\section{Agar}

Mannitol Salt Agar (Difco)

MacConkey Agar (Difco)

Rogosa SL Agar (Difco)

Azide Blood Agar (Difco)

$+5 \%$ horse blood

RCM Agar (Oxoid) (pre-

reduced) + haemin-vitamin $\mathrm{K}$

$+7.5 \%$ horse blood

RCM Agar (Oxoid) + haemin-

vitamin $\mathrm{K}+7.5 \%$ horse blood

Veillonella Agar (Difco)

Willis-Hobbs Agar

(Cruickshank et al., 1964)

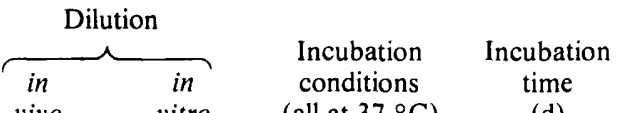

vivo vitro (all at $37^{\circ} \mathrm{C}$ )

(d)

$10^{-1} \quad 10^{0} \quad$ Aerobic

$10^{-3} \quad 10^{-3} \quad$ Aerobic $\quad 2$

$10^{-5} \quad 10^{-5} \quad$ Anaerobic $\quad 3$

$10^{-5} \quad 10^{-5} \quad$ Aerobic $\quad 3$

$10^{-6} \quad 10^{-6} \quad$ Anaerobic $\quad 3$

$10^{-6} \quad 10^{-6} \quad$ Aerobic

$10^{-2} \quad 10^{-1} \quad$ Anaerobic $\quad 3$

$10^{-4} \quad 10^{-3} \quad$ Anaerobic $\quad 3$

\section{RESULTS}

\section{Recovery of micro-organisms}

The faecal and continuous culture viable counts ( \pm standard error of the mean) on pre-reduced RCM-blood agar plates inoculated on the open bench were $76.7 \pm 3.1 \%$ and $81.5 \pm 5.1 \%$, respectively, of the viable counts on the same agar determined by the use of strictly anaerobic procedures (roll tubes). All species and colonial types isolated in the roll tubes were observed on the pre-reduced RCM-blood agar plates. The relative proportions of the most common species ( 95 to $98 \%$ of the total isolated community) found on the pre-reduced plates were not significantly different, as judged by the chi-square test of Freund (1971), from those observed in roll tubes $(P>0.10$ for faecal and continuous culture samples).

The total viable counts (determined from the number of colonies on plates of RCM-blood agar incubated aerobically and anaerobically) for faecal and continuous culture samples were $95.2 \pm 2.1 \%$ and $93.1 \pm 3.9 \%$, respectively, of the direct microscopic count for these samples.

Thus, the use of strict anaerobic techniques such as the roll tube method was not necessary for a valid comparison of the faecal and continuous culture anaerobic communities.

The number of enterobacteria and streptococci recovered on selective media (MacConkey and Azide Blood Agars, respectively) was not significantly different from the number observed on the non-selective, aerobically incubated RCM-blood agar ( $t$-test, $P>0 \cdot 10$ ) (Sokal \& Rohlf, 1969). The proportions of the various species contained in these two groups were not significantly different between the selective and non-selective media (chi-square test, $P>0 \cdot 05$ ).

It was not possible to determine the efficiency of recovery of the staphylococci and lactobacilli. The staphylococci were present in low numbers and never identified at the dilution used for the total aerobic count. The recovery of lactobacilli on pre-reduced RCM-blood agar (anaerobic incubation) was always less than that observed on Rogosa SL Agar. However, the numbers observed in the faeces were similar to those reported in other studies (Drasar et al., 1969). 
Table 2. Comparison of faecal bacterial group proportions and numerical abundance within and between rat strains (Wistar and Sprague Dawley)

The total viable count was determined from the sum of the mean number of colonies on RCM-blood agar incubated aerobically and anaerobically over the entire sampling period ( 7 months). Results are shown \pm 1 standard error (S.E.). For the statistical comparisons, $\chi_{w}^{2}$ and $\chi_{\text {sd }}^{2}$ show the chi-square values for the comparison of the differences, for a bacterial group, between individual rats of a given strain (Wistar and Sprague Dawley, respectively). The $\chi_{b t}^{2}$ shows the difference between the two rat strains. The $\chi_{\text {num }}^{2}$ indicates the significance of the difference in numerical abundance of a bacterial group between rat strains. ${ }^{*}$ indicates a significant $\chi^{2}$ value, $P<0.05$.

\begin{tabular}{|c|c|c|c|c|c|c|}
\hline \multirow[b]{2}{*}{ Bacterial group } & \multicolumn{2}{|c|}{ Percentage of total viable count $( \pm$ S.E. $)$} & \multicolumn{4}{|c|}{ Statistical comparison } \\
\hline & Wistar & Sprague Dawley & $\chi_{w}^{2}$ & $\chi_{\mathrm{sd}}^{2}$ & $\chi_{\mathrm{bt}}^{2}$ & $\chi_{\text {num }}^{2}$ \\
\hline Staphylococci & $0.04 \pm 0.06$ & $0.0006 \pm 0.0006$ & $6 \cdot 2$ & $3 \cdot 1$ & $39 \cdot 0^{*}$ & $12 \cdot 4^{*}$ \\
\hline Enterobacteria & $0.28 \pm 0.12$ & $0.78 \pm 0.34$ & $4 \cdot 3$ & $3 \cdot 2$ & $11 \cdot 9^{*}$ & $16 \cdot 1^{*}$ \\
\hline Lactobacilli & $26.4 \pm 9.2$ & $11 \cdot 3 \pm 7 \cdot 3$ & 1.4 & 1.4 & $372 \cdot 6^{*}$ & $24 \cdot 7^{*}$ \\
\hline Anaerobes & $51 \cdot 3 \pm 13 \cdot 1$ & $80.7 \pm 9.8$ & $5 \cdot 3$ & $4 \cdot 4$ & $96 \cdot 9^{*}$ & $31 \cdot 4^{*}$ \\
\hline Streptococci & $22 \cdot 0 \pm 8 \cdot 3$ & $7 \cdot 2 \pm 4 \cdot 1$ & $2 \cdot 2$ & $4 \cdot 1$ & $439 \cdot 1^{*}$ & $34 \cdot 1^{*}$ \\
\hline $10^{-9} \times$ & & & & & & \\
\hline $\begin{array}{l}\text { Total viable count } \\
\text { [cells ( } \mathrm{g} \text { faeces })^{-1} \text { | }\end{array}$ & $7 \cdot 24 \pm 2.63$ & $9.55 \pm 3.63$ & & & & \\
\hline
\end{tabular}

\section{The rat hindgut ecosystem}

The species composition and community structure was determined for the faeces of five Wistar and two Sprague Dawley rats sampled at least five times a week over 7 months. In both strains of rats the anaerobes, lactobacilli and streptococci formed the major populations. The enterobacteria and staphylococci were minor members of the community (Table 2). The proportion of the total community and the numerical abundance for each bacterial group was not significantly different between rats of the same strain but was significantly different between strains (Table 2). The density of the bacterial groups was to some extent dependent on the individual within a strain, as indicated by the Student-Newman-Keuls test (Sokal \& Rohlf, 1969).

The most common species found in the faeces of Wistar and Sprague Dawley rats are shown in Table 3. The species composition flora was qualitatively similar between strains with the notable exception of Bacteroides fragilis subsp. thetaiotaomicron which was only found in the Sprague Dawley rats. The community structure, in terms of the ranking of species on the basis of their numerical abundance among individuals of the same strain, was not significantly different as determined by the Kendall coefficient of concordance, W (Siegel, 1956). W measures the degree of association between several ranked sets of species (Table 4). The rank of a species in the community structure was determined according to its daily mean abundance (daily rank) and overall mean abundance (overall rank) over a period of 7 months. The structure determined by these two methods was the same. It should be noted that using the overall mean species abundance to rank position in the community structure is valid if the frequency-abundance distribution of the species is not highly skewed (Lewis, 1977). The skewness of individual species of a given bacterial group (Table 4; calculated by method of Sokal \& Rohlf, 1969) was always less than that for the group itself. This is because the group frequency-abundance distribution is a function of the contributions of all species composing the group. For example, in the anaerobes (Wistar rats), Bacteroides fragilis subsp. vulgatus exhibited the greatest species skew $(0 \cdot 36)$. The community structure was different between rat strains for the anaerobes, lactobacilli and streptococci (Table 4) although the species composition of the communities was similar (Table 3 ). 
Table 3. Comparison of the most common micro-organisms in faecal samples from different rat strains (Wistar and Sprague Dawley)

The results are for a representative individual from each strain. The species are listed in order of numerical abundance. Values in parentheses show the abundance of each species as a percentage of the total viable count for that bacterial group; where no values are given, the species contributed less than $1 \%$ of the total group count. Isolates followed by (?) were tentatively identified. Organisms unidentified at the species level are distinguished from other unidentified species of the same genera by alphabetical superscripts.

Bacterial group

Staphylococci

Enterobacteria

Staphylococcus aureus

Wistar

Escherichia coli $(95 \%)$

Proteus mirabilis (4\%)

Klebsiella pneumoniae

Pseudomonads Not detected

Lactobacilli Lactobacillus acidophilus (64\%)

L. delbrueckii (18\%)

L. plantarum $(5 \%)$

L. lactis

L. brevis

L. fermentum

Streptococci Streptococcus salivarius (98\%)

S. faecalis

S. mitis

S. sanguis

S. viridans

Anaerobes
Sprague Dawley

\section{Staphylococcus aureus}

Escherichia coli (74\%)

Proteus mirabilis (18\%)

Klebsiella pneumoniae

Pseudomonas aeruginosa

Lactobacillus plantarum (55\%)

L. acidophilus (35\%)

L. brevis (4\%)

L. lactis

L. buchneri

L. leichmannii

Streptococcus salivarius (94\%)

S. sanguis (5\%)

S. mitis

S. faecalis

Bacteroides fragilis subsp. thetaiotaomicron (40\%)

Bacteroides fragilis subsp. fragilis (30\%)

Bacteroides melaninogenicus

Bacteroides sp. ${ }^{b}$ (?)

Bacteroides oralis

Bifidobacterium bifidum

Peptostreptococcus sp. (?)

Table 4. Comparison of the faecal community structure within and between rat strains (Wistar and Sprague Dawley)

SK is the skewness statistic (Sokal \& Rohlf, 1969), W is the Kendall coefficient of concordance, and $\mathrm{df}$ is the number of species minus 1 . The only species observed for the staphylococci of both rats was $S$. aureus and $\mathrm{W}$ cannot be calculated in this case. ${ }^{*}$ indicates a significant $\chi^{2}$ value $(P<0.05)$ for the $\mathrm{W}$ statistic indicating the relative rankings within a group are the same and not significantly different. A non-significant $\chi^{2}$ implies that the species rankings are not similar.

\begin{tabular}{|c|c|c|c|c|c|c|c|c|c|c|c|}
\hline \multirow[b]{2}{*}{ Bacterial group } & \multicolumn{4}{|c|}{ Wistar } & \multicolumn{4}{|c|}{ Sprague Dawley } & \multicolumn{3}{|c|}{ Between strains } \\
\hline & SK & W & $\chi^{2}$ & df & SK & $\mathbf{w}$ & $\chi^{2}$ & $\mathrm{df}$ & W & $\chi^{2}$ & $\mathrm{df}$ \\
\hline Staphylococci & 0.92 & - & - & - & $1 \cdot 23$ & - & - & - & - & - & - \\
\hline Enterobacteria & 0.30 & 0.91 & $15 \cdot 1^{*}$ & 4 & 0.47 & 0.99 & $40 \cdot 4^{*}$ & 3 & 0.94 & $16 \cdot 7^{*}$ & 4 \\
\hline Lactobacilli & 0.63 & 0.96 & $20 \cdot 1^{*}$ & 6 & 0.68 & 1.00 & $100 \cdot 0^{*}$ & 7 & 0.13 & 3.4 & 7 \\
\hline Anaerobes & 0.73 & 0.97 & $39.7^{*}$ & 9 & 0.51 & 0.95 & $29 \cdot 3^{*}$ & 7 & 0.05 & 0.54 & 9 \\
\hline Streptococci & 0.51 & 0.93 & $26 \cdot 4^{*}$ & 4 & 0.43 & 0.99 & $31 \cdot 4^{*}$ & 4 & $0 \cdot 24$ & $1 \cdot 73$ & 4 \\
\hline
\end{tabular}

\section{Growth of rat faecal microflora in continuous culture}

\section{Single-stage continuous culture}

For these experiments, the cultures were operated at low dilution rates $\left(0.04\right.$ to $\left.0.18 \mathrm{~h}^{-1}\right)$ in order to approximate the flow regime of the gut (Gibbons \& Kapsimalis, 1967). The pH of the cultures was chosen on the basis of in vivo measurements which for male Wistar rats were 
Table 5. Comparison of bacterial group proportions in single-stage continuous cultures operating at different dilution rates and $\mathrm{pH}$ values

The percentage of the total viable count contributed by a group was determined at the steady state (as defined in the text).

\begin{tabular}{|c|c|c|c|c|c|c|c|}
\hline \multirow{2}{*}{$\begin{array}{l}\mathrm{pH} \\
\text { value }\end{array}$} & \multirow{2}{*}{$\begin{array}{c}\text { Dilution } \\
\text { rate } \\
\left(h^{-1}\right)\end{array}$} & \multirow{2}{*}{$\begin{array}{c}10^{-7} \times \text { Total } \\
\text { viable count } \\
\left(\text { cells } \mathrm{ml}^{-1}\right)\end{array}$} & \multicolumn{5}{|c|}{ Percentage of total viable count $( \pm$ S.E.) } \\
\hline & & & Staphylococci & Enterobacteria & Lactobacilli & Anaerobes & Streptococci \\
\hline $5 \cdot 1$ & $\begin{array}{l}0.04 \\
0.18\end{array}$ & $\begin{array}{l}4.37 \\
7.59\end{array}$ & - & - & $\begin{array}{l}46 \pm 2 \\
54 \pm 3\end{array}$ & $\begin{array}{r}23 \pm 3 \\
9 \pm 3\end{array}$ & $\begin{array}{l}31 \pm 1 \\
37 \pm 1\end{array}$ \\
\hline $5 \cdot 5$ & $\begin{array}{l}0.04 \\
0.10 \\
0.18\end{array}$ & $\begin{array}{r}6 \cdot 92 \\
14 \cdot 45 \\
21 \cdot 88\end{array}$ & $\begin{array}{l}- \\
- \\
-\end{array}$ & $\begin{array}{r}4 \pm 0.9 \\
1 \pm 0.5 \\
0.3 \pm 0.1\end{array}$ & $\begin{array}{l}14 \pm 2 \\
25 \pm 3 \\
41 \pm 2\end{array}$ & $\begin{array}{l}28 \pm 5 \\
16 \pm 1 \\
24 \pm 2\end{array}$ & $\begin{array}{l}54 \pm 3 \\
58 \pm 4 \\
35 \pm 3\end{array}$ \\
\hline $6 \cdot 0$ & 0.04 & $43 \cdot 65$ & - & $31 \pm 2$ & - & $34 \pm 3$ & $35 \pm 1$ \\
\hline $7 \cdot 1$ & $\begin{array}{l}0.04 \\
0.09\end{array}$ & $\begin{array}{l}67 \cdot 61 \\
87 \cdot 10\end{array}$ & $\begin{array}{l}- \\
-\end{array}$ & $\begin{array}{l}4 \pm 1 \\
3 \pm 0 \cdot 5\end{array}$ & - & $\begin{array}{l}79 \pm 4 \\
84 \pm 3\end{array}$ & $\begin{array}{l}17 \pm 3 \\
13 \pm 1\end{array}$ \\
\hline
\end{tabular}

-. Group not detected at a sampling dilution of $10^{\circ}$.

found to be: stomach, $4 \cdot 1$; proximal ileum, $6 \cdot 7$; distal ileum, $7 \cdot 1$; caecum, $6 \cdot 7$; hindgut, $7 \cdot 1$ (I. Rowland, unpublished observations). As this study was concerned with the hindgut flora, the initial cultures were operated at a $\mathrm{pH} 7 \cdot 1$. However, the failure of these cultures to resemble the in vivo flora led to the use of three other $\mathrm{pH}$ regimes $-6 \cdot 0,5 \cdot 5$ and $5 \cdot 1$. These experiments are summarized in Table 5 for a Wistar inoculum. The majority of experiments were carried out using Wistar rats as the source of inocula and, unless otherwise stated, the in vitro results pertain to this strain.

The proportions of the main groups of bacteria at the steady state (defined below) were dependent on both the dilution rate and culture $\mathrm{pH}$ (Table 5). The persistence of a group in a culture was independent of the dilution rate over the range investigated. The maintenance of the lactobacilli and enterobacteria was dependent on the $\mathrm{pH}$ value of the culture. At $\mathrm{pH} 5 \cdot 1$, the enterobacteria, staphylococci and the majority of the anaerobes were lost from the systems. At pH 6.0 and $7 \cdot 1$, the enterobacteria (mainly Proteus sp.), anaerobes and streptococci dominated the cultures, while the lactobacilli and staphylococci washed out. At $\mathrm{pH} 5 \cdot 5$, the staphylococci were lost, but all the other groups were maintained in proportions which depended on the dilution rate (Table 5). The community structure was not comparable with that observed in vivo, an observation exemplified by the lactobacilli (compare Tables 3 and 6). A similar situation was observed for all the bacterial groups.

In all cultures, the numerical abundance of the populations fluctuated with time, despite maintaining constant environmental conditions: all populations exhibited statistically random changes (run-test; Siegel, 1956), which were greater in magnitude than the error due to sampling. Steady-state cultures were defined as those in which the populations showed no significant overall increase or decrease in their abundance for at least 15 cell generations. This was determined by regression analysis (Sokal \& Rohlf, 1969), the criteria being that the slope of the regression of abundance with time was not significantly different from zero. The numerical density of a population at the steady state was taken as the mean of the observations over this time. The frequency-abundance distribution of the bacterial groups was tested for skewness (Sokal \& Rohlf, 1969) and no skew was observed. The relative proportions of the bacterial groups were determined at the steady state.

The results of the single-stage cultures indicated that such systems could not simulate the community structure of the gut. Thus, in order to provide favourable environmental conditions for all groups (e.g. low $\mathrm{pH}$ for the lactobacilli and more neutral $\mathrm{pH}$ for the anaerobes and enterobacteria) an in vitro system with differential culture conditions was required. 
Table 6. Community composition and structure of the most common lactobacilli in continuous cultures operating under different regimes For each culture regime, the species are listed in order of numerical abundance. Values in parentheses
show the abundance of each species as a percentage of the total count of lactobacilli.

$\begin{array}{ll}\begin{array}{l}\text { Single-stage culture } \\ \mathrm{pH} 5 \cdot 1\left(D=0 \cdot 18 \mathrm{~h}^{-1}\right)\end{array} & \begin{array}{l}\text { Single-stage culture } \\ \mathrm{pH} 5 \cdot 5\left(D=0 \cdot 10 \mathrm{~h}^{-1}\right)\end{array} \\ \text { L. acidophilus }(96 \%) & \text { L. acidophilus }(94 \%) \\ \text { L. lactis }(4 \%) & \text { L. lactis }(4 \%) \\ \text { Two-stage culture without cell recycle: } \text { system } B\left(D=0 \cdot 11 \mathrm{~h}^{-1}\right) \\ \quad \text { Stage I: } \mathrm{pH} 5 \cdot 1 & \text { Stage II: } \mathrm{pH} 7 \cdot 1 \\ \text { L. acidophilus }(96 \%) & \text { L. acidophilus }(83 \%) \\ \text { L. lactis }(4 \%) & \text { L. lactis }(15 \%) \\ & \text { L. delbrueckii }(2 \%) \\ & \text { L. plantarum }\end{array}$

\begin{tabular}{ll}
\multicolumn{1}{c}{ Two-stage culture with cell recycle: } & \multicolumn{1}{c}{ system $E\left(D=0.07 \mathrm{~h}^{-1}\right)$} \\
\multicolumn{1}{c}{ Stage I: $\mathrm{pH} 5 \cdot 1$} & Stage II: $\mathrm{pH} 7 \cdot 1$ \\
L. acidophilus $(93 \%)$ & L. acidophilus $(79 \%)$ \\
L. delbrueckii $(4 \%)$ & L. plantarum $(10 \%)$ \\
L. plantarum $(3 \%)$ & L. delbrueckii $(4 \%)$ \\
L. lactis & Streptobacterium $\mathrm{sp} .(3 \%)$ \\
L. fermentum & L. lactis $(2 \%)$ \\
& L. brevis \\
L. fermentum
\end{tabular}

\begin{tabular}{ll} 
Two-stage culture with cell recycle: & \multicolumn{1}{c}{ system $D(D=0 \cdot 07$} \\
Stage I: $\mathrm{pH} 5 \cdot 5$ & Stage II: $\mathrm{pH} 7 \cdot 1$ \\
L. acidophilus $(94 \%)$ & L. acidophilus $(84 \%)$ \\
L. lactis $(5 \%)$ & L. delbrueckii $(8 \%)$ \\
L. plantarum $(1 \%)$ & L. lactis $(5 \%)$ \\
& L. plantarum $(2 \%)$ \\
L. fermentum $(1 \%)$
\end{tabular}

\section{Two-stage continuous culture without cell recycling}

Two-stage cultures were operated under two $\mathrm{pH}$ regimes, $\mathrm{A}$ and $\mathrm{B}$. For the A conditions, the $\mathrm{pH}$ of both stages (I and II) was set at $7 \cdot 1$. Under B conditions, the $\mathrm{pH}$ of stage I was fixed at $5 \cdot 1$ and that of stage II at $7 \cdot 1$. For both $\mathrm{pH}$ systems, a constant dilution rate of $0.11 \mathrm{~h}^{-1}$ through both stages was used.

The first stages in the A and B systems were equivalent to the corresponding single-stage cultures and so the steady-state bacterial group proportions were similar (Table 7). The bacterial group composition in the second stage of system A was not qualitatively different from the first stage, as indicated by the $\mathrm{W}$ statistic which was not significantly different between the stages for the anaerobes, enterobacteria or streptococci (Table 7). However, the microbial community of stage II of the system B differed both qualitatively and quantitatively from stage I (Table 6). For all bacterial groups, the $\mathrm{W}$ statistic was significantly different between the two stages. The community structure of both stages was not similar to that found in the faeces. Although the species found in the in vitro cultures were observed in faecal samples, the overall diversity of species was much less in vitro (discussed below). Another characteristic of these cultures was the formation in stage II of significant wall growth, composed mainly of lactobacilli and some anaerobes. Wall growth was found in all cultures but not to the extent observed in stage II of system B cultures.

\section{Two-stage continuous cultures with cell recycling}

Observations of the changes in species composition with time in the B system cultures (stage I, pH 5.1; stage II, pH 7.1) without cell recycling indicated that a defined succession of species occurred (B. G. Veilleux \& I. Rowland, unpublished results). Although a large number 
Table 7. Comparison of bacterial group proportions in two-stage continuous cultures operating without cell recycling at a dilution rate of $0 \cdot 11 \mathrm{~h}^{-1}$

\begin{tabular}{|c|c|c|c|c|c|c|}
\hline & \multirow{2}{*}{$\begin{array}{c}10^{-7} \times \text { Total } \\
\text { viable count } \\
\left(\text { cells } \mathrm{ml}^{-1}\right)\end{array}$} & \multicolumn{5}{|c|}{ Percentage of total viable count $( \pm$ S.E. $)$} \\
\hline & & Staphylococci & Enterobacteria & Lactobacilli & Anaerobes & Streptococci \\
\hline \multicolumn{7}{|l|}{ System A } \\
\hline $\begin{array}{r}\text { Stage I: } \\
\text { pH } 7 \cdot 1\end{array}$ & 43.65 & - & $1 \pm 0 \cdot 1$ & - & $83 \pm 4$ & $16 \pm 1$ \\
\hline $\begin{array}{r}\text { Stage II: } \\
\mathrm{pH} 7 \cdot 1\end{array}$ & $81 \cdot 28$ & - & $1 \pm 0 \cdot 3$ & - & $91 \pm 3$ & $8 \pm 1$ \\
\hline \multicolumn{7}{|l|}{ System B } \\
\hline $\begin{array}{l}\text { Stage I: } \\
\text { pH } 5 \cdot 1\end{array}$ & 6.46 & - & - & $43 \pm 2$ & $27 \pm 4$ & $30 \pm 2$ \\
\hline $\begin{array}{r}\text { Stage II: } \\
\text { pH } 7 \cdot 1\end{array}$ & $53 \cdot 70$ & - & $2 \pm 0.5$ & $4 \pm 0.4$ & $88 \pm 3$ & $5 \pm 0.4$ \\
\hline
\end{tabular}

Table 8. Effect of stage $\mathrm{pH}$ on bacterial group proportions in two-stage continuous cultures operating with cell recycling at a dilution rate of $0.07 \mathrm{~h}^{-1}$

\begin{tabular}{|c|c|c|c|c|c|c|}
\hline \multirow[b]{3}{*}{ Bacterial group } & \multicolumn{6}{|c|}{ Percentage of total viable count $( \pm$ S.E. $)$} \\
\hline & \multicolumn{2}{|c|}{ System C } & \multicolumn{2}{|c|}{ System D } & \multicolumn{2}{|c|}{ System E } \\
\hline & $\begin{array}{l}\text { Stage I } \\
\mathrm{pH} 7.1\end{array}$ & $\begin{array}{c}\text { Stage II } \\
\mathrm{pH} 7.1\end{array}$ & $\begin{array}{l}\text { Stage I } \\
\text { pH 5.5 }\end{array}$ & $\begin{array}{l}\text { Stage II } \\
\mathrm{pH} 7 \cdot 1\end{array}$ & $\begin{array}{l}\text { Stage I } \\
\text { pH } 5 \cdot 1\end{array}$ & $\begin{array}{l}\text { Stage II } \\
\mathrm{pH} 7 \cdot 1\end{array}$ \\
\hline $\begin{array}{l}\text { Staphylococci } \\
\text { Enterobacteria } \\
\text { Lactobacilli } \\
\text { Anaerobes } \\
\text { Streptococci }\end{array}$ & $\begin{aligned} &- \\
& 2 \pm 0.4 \\
&- \\
& 77 \pm 3 \\
& 21 \pm 1\end{aligned}$ & $\begin{array}{c}- \\
3 \pm 0 \cdot 3 \\
- \\
81 \pm 4 \\
16 \pm 1\end{array}$ & $\begin{aligned} & - \\
1 & \pm 0 \cdot 1 \\
16 & \pm 0.7 \\
48 & \pm 0.9 \\
35 & \pm 2\end{aligned}$ & $\begin{array}{c}- \\
10 \pm 1 \\
2 \pm 0 \cdot 3 \\
65 \pm 4 \\
23 \pm 2\end{array}$ & $\begin{array}{c}- \\
0.21 \pm 0.9 \\
19 \pm 2 \\
65 \pm 3 \\
16 \pm 1\end{array}$ & $\begin{array}{l}- \\
3 \pm 0.4 \\
4 \pm 0.4 \\
71 \pm 2 \\
22 \pm 1\end{array}$ \\
\hline $10^{-8} \times$ Total viable count & 4.07 & 10.47 & $2 \cdot 46$ & $11 \cdot 22$ & 1.70 & $12 \cdot 88$ \\
\hline
\end{tabular}

- , Group not detected at a sampling dilution of $10^{\circ}$.

of species were observed after batch growth, this number declined until the final steady state was reached. It was found that by inoculating a small amount of faeces $(0.05 \mathrm{ml}$ faecal suspension) to stage I after the steady state was reached (150 to $250 \mathrm{~h}$ ) some of the lactobacilli species initially lost during the successional development to the steady state, grew and persisted in this stage. It appeared that the biotic and abiotic environment in the culture changed sufficiently with time to encourage the growth of some species which found the earlier conditions in the culture unsuitable. In the rat, re-introduction of species to the ecosystem continually occurs due to coprophagy. To simulate this condition, system B cultures were operated with cell recycling. In these systems, culture medium from stage II was recycled to stage $I$ at one-tenth of the rate of flow of sterile medium. The results of these experiments are summarized in Tables 6 and 8. Only in those cultures with different $\mathrm{pH}$ values in the two stages ( $D$ and $E$ systems) did the proportions of the bacterial groups resemble those in the faecal samples (compare Tables 2 and 8). On the basis of bacterial group proportions, stage I of the E systems resembled the rat faecal samples most closely. Stage II of these systems, however, showed a species composition similar to that found in the faeces (Table 9). The staphylococci were lost from these cultures. 
Table 9. Comparison of the most common micro-organisms in samples from continuous cultures with different faecal inocula (Wistar and Sprague Dawley)

Two-stage continuous cultures were operated with cell recycling at a dilution rate of $0.07 \mathrm{~h}^{-1}$ (system E): results are for samples taken from stage II. For other details, see legend to Table 3.

Bacterial group

Staphylococci

Enterobacteria

Pseudomonads

Lactobacilli
Wistar inocula

Not detected

Escherichia coli (78\%)

Proteus mirabilis (18\%)

Not detected

Lactobacillus acidophilus (79\%)

L. plantarum (10\%)

L. delbrueckii (4\%)

Streptobacterium sp. (?) (3\%)

L. lactis (2\%)

L. brevis

L. fermentum

Streptococcus salivarius (92\%)

S. faecalis subsp. zymogenes (6\%)

S. faecalis (2\%)

S. bovis

S. durans

S. sanguis
Sprague Dawley inocula

Staphylococcus aureus

Escherichia coli (94\%)

Proteus mirabilis (6\%)

Pseudomonas aeruginosa

Lactobacillus plantarum (54\%)

L. acidophilus (31\%)

L. brevis $(8 \%)$

L. viridescens $(6 \%)$

Lactobacillus sp. (?)

L. lactis

Streptococcus salivarius (81\%)

S. faecalis (15\%)

S. sanguis $(3 \%)$

S. bovis

S. mitis

Bacteroides fragilis subsp. thetaiotaomicron (55\%)

Bacteroides melaninogenicus (20\%)

Bacteroides fragilis subsp. vulgatus (16\%)

Bifidobacterium sp." (?) (3\%)

Bacteroides sp. ${ }^{\mathrm{b}}$ (?)

Clostridium sp. ${ }^{\mathrm{a}}$ (?)

Bifidobacterium bifidum

Although the proportions of the bacterial groups reached approximately constant values after about 150 to $250 \mathrm{~h}$ for stage I and 100 to $200 \mathrm{~h}$ for stage II, a defined succession of species within the groups occurred up to $400 \mathrm{~h}$. After this time, the structure of the bacterial groups remained approximately constant showing no significant changes in species composition. In one system, the community structure of all bacterial groups remained unchanged from 408 to $1272 \mathrm{~h}$ when the experiment was ended. The structure of the in vitro communities was dependent upon the dilution rate. These results are summarized in Table 10. The structure of the in vitro community was most similar to the faecal structure when the dilution rate through the cultures was low $\left(0.04\right.$ to $\left.0.13 \mathrm{~h}^{-1}\right)$.

\section{Source of inoculum and the final community structure in vitro with cell recycling}

The final community established in vitro depended on the source of the inoculum. The community structure for the $\mathrm{E}$ system reflected the bacterial group proportions (compare Tables 11 and 2) and the species composition (compare Tables 9 and 3) of the rat strain from which the inoculum was taken. For example, cultures inoculated with faeces from a Sprague Dawley rat reflected the relatively low numbers of lactobacilli and streptococci with respect to the anaerobe density observed in faecal samples (Table 2). Again, the higher proportions of lactobacilli and streptococci in the faeces of Wistar rats were reflected in the in vitro cultures derived from such inocula. The effect can also be illustrated by comparing the abundance of the clostridia and veillonellae between the two rat strains and their steady-state densities in vitro. These two anaerobe groups were not studied extensively. They served as an additional test case for the comparison of the in vitro and in vivo systems. In the faecal samples, the mean abundances of the clostridia and veillonellae were: Wistar rats $-10^{3}$ to $10^{4}$ clostridia $\mathrm{g}^{-1}, 10^{1}$ to $10^{1 \cdot 5}$ veillonellae $\mathrm{g}^{-1}$; Sprague Dawley rats $-10^{5}$ to $10^{5 \cdot 6}$ clostridia $\mathrm{g}^{-1}, 10^{3}$ 
Table 10. Effect of dilution rate on bacterial group proportions in two-stage continuous cultures operating with cell recycling (system $E$ )

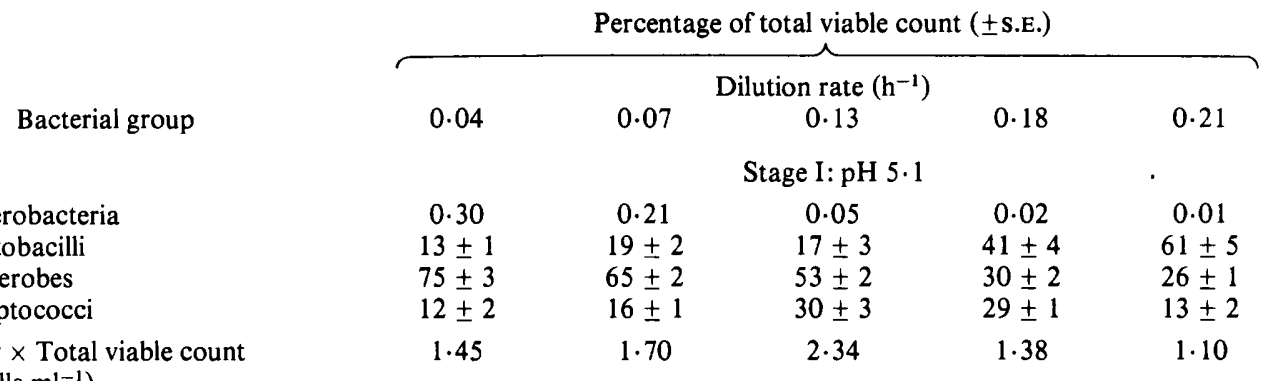

$10^{-8} \times$ Total viable count (cells $\mathrm{ml}^{-1}$ )

Stage II: $\mathrm{pH} 7 \cdot 1$

Enierobacteria
Lactobacilli
Anaerobes
Streptococci
$10^{-8} \times$ Total viable count
$\left(\right.$ cells $\left.\mathrm{ml}^{-1}\right)$

$\begin{array}{cc}6 \pm 0.4 & 3 \pm 0.3 \\ 3 \pm 0.9 & 4 \pm 0.7 \\ 79 \pm 2 & 71 \pm 3 \\ 12 \pm 1 & 22 \pm 2 \\ 10.96 & 12.88\end{array}$

$5 \pm 1$
$6 \pm 1$
$74 \pm 3$
$15 \pm 2$
$17 \cdot 38$

$6 \pm 1$
$28 \pm 3$
$47 \pm 2$
$20 \pm 2$
$16 \cdot 22$

$6 \pm 2$

$37 \pm 3$

$41 \pm 2$

$16 \pm 3$

11.48

Table 11. Effect of initial inoculum on bacterial group proportions in two-stage continuous cultures operating with cell recycling at a dilution rate of $0.07 \mathrm{~h}^{-1}$ (system E)

Bacterial group

Enterobacteria
Lactobacilli
Anaerobes
Streptococci
$10^{-8} \times$ Total viable count (cells $\mathrm{ml}^{-1}$ )

\begin{tabular}{|c|c|c|c|}
\hline \multicolumn{4}{|c|}{ Percentage of total viable count $( \pm$ S.E.) } \\
\hline \multicolumn{2}{|c|}{ Inoculum from Wistar rat } & \multicolumn{2}{|c|}{ Inoculum from Sprague Dawley rat } \\
\hline $\begin{array}{l}\text { Stage I } \\
\mathrm{pH} 5 \cdot 1\end{array}$ & $\begin{array}{l}\text { Stage II } \\
\text { pH } 7.1\end{array}$ & $\begin{array}{l}\text { Stage I } \\
\mathrm{pH} 5.1\end{array}$ & $\begin{array}{c}\text { Stage II } \\
\mathrm{pH} 7.1\end{array}$ \\
\hline $\begin{array}{c}0.21 \pm 0.9 \\
19 \pm 2 \\
65 \pm 3 \\
16 \pm 1\end{array}$ & $\begin{array}{l}3 \pm 0.4 \\
4 \pm 0.4 \\
71 \pm 2 \\
22 \pm 1\end{array}$ & $\begin{array}{c}0.45 \pm 0.1 \\
10 \pm 3 \\
83 \pm 1 \\
7 \pm 3\end{array}$ & $\begin{aligned} 1 & \pm 0 \cdot 5 \\
3 & \pm 1 \\
94 & \pm 4 \\
2 & \pm 1\end{aligned}$ \\
\hline $1 \cdot 70$ & $12 \cdot 88$ & 1.95 & 10.47 \\
\hline
\end{tabular}

veillonellae $\mathrm{g}^{-1}$. The differences in these organisms between rat strains are significant at the 0.001 level (Student's $t$-test). The steady-state densities of these organisms in vitro (system E, stage II, $D=0.07 \mathrm{~h}^{-1}$ ) were: Wistar inoculum $-10^{2 \cdot 5}$ clostridia $\mathrm{ml}^{-1}, 10^{0.5}$ veillonellae $\mathrm{ml}^{-1}$; Sprague Dawley inoculum $-10^{5}$ clostridia $\mathrm{ml}^{-1}, 10^{2}$ veillonellae $\mathrm{ml}^{-1}$. The differences are significant at the 0.001 level and reflect the composition of the original inoculum. In addition, in cultures using inoculum from a Sprague Dawley rat, staphylococci ( $S$. aureus) were

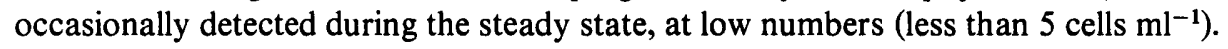

\section{Effect of culture complexity on species diversity}

The species diversity within the lactobacilli, anaerobes and streptococci communities of faecal samples and different culture regimes was calculated using the method of Pielou (1975) and is shown in Table 12. Because of the inability of the sampling method to detect very rare species (at density yielding less than one colony on the three sample plates at a given dilution) the diversity values are less than the true diversity. The index used here does take this partially into account and is based on the cumulative total of all observations (Pielou, 1975). The values in Table 12 serve only as a rough indication of the actual species diversity of the ecosystems. Diversity depends on both the number of species and the evenness with which 
Table 12. The diversity and evenness within lactobacilli, anaerobes and streptococci communities of faecal samples and continuous culture systems

The faecal samples and inoculum for the in vitro cultures were from a Wistar rat. D is the diversity index and $\mathrm{E}$ is the measure of evenness (Pielou, 1975).

\begin{tabular}{|c|c|c|c|c|c|c|}
\hline & Lac & cilli & & & Stre & cocci \\
\hline & $\mathrm{D}$ & $\mathrm{E}$ & D & $\mathrm{E}$ & $\mathrm{D}$ & $\mathrm{E}$ \\
\hline Faecal sample & 0.32 & 0.31 & 0.53 & 0.41 & 0.05 & 0.08 \\
\hline Single-stage, pH $5.5\left(D=0.10 \mathrm{~h}^{-1}\right)$ & $0 \cdot 10$ & 0.32 & 0.06 & 0.19 & 0.23 & 0.49 \\
\hline $\begin{array}{l}\text { Two-stage without recycle: system B } \\
\left(D=0.11 \mathrm{~h}^{-1}\right)\end{array}$ & & & & & & \\
\hline Stage I: $\mathrm{pH} 5 \cdot 1$ & 0.07 & 0.24 & 0.03 & $0 \cdot 11$ & 0.18 & 0.34 \\
\hline Stage II: pH $7 \cdot 1$ & 0.23 & $0 \cdot 37$ & $0 \cdot 31$ & 0.44 & 0.24 & 0.27 \\
\hline $\begin{array}{l}\text { Two-stage with recycle: system } \mathrm{E} \\
\left(D=0.07 \mathrm{~h}^{-1}\right)\end{array}$ & & & & & & \\
\hline
\end{tabular}

Table 13. Comparison of population variation in faecal samples and in two-stage continuous cultures operating with cell recycling (system $E$ )

The faecal samples and inoculum for the in vitro cultures were from a Wistar rat. $n$ is the number of observations, $X_{1}$ and $X_{2}$ are the mean cell density $\left(\log _{10}\right)$ per $g$ faeces or per $\mathrm{ml}$ culture medium, respectively, $S$ is the logarithmic deviation, and $C F$ is the coefficient of fluctuation.

\begin{tabular}{|c|c|c|c|c|c|c|c|c|c|c|c|c|}
\hline \multirow[b]{3}{*}{ Bacterial group } & \multicolumn{4}{|c|}{ In vivo } & \multicolumn{8}{|c|}{ In vitro } \\
\hline & \multicolumn{4}{|c|}{ Faecal samples } & \multicolumn{4}{|c|}{ Stage I: pH $5 \cdot 1$} & \multicolumn{4}{|c|}{ Stage II: $\mathrm{pH} 7 \cdot 1$} \\
\hline & $n$ & $\mathrm{X}_{1}$ & S & $\mathrm{CF}$ & $n$ & $\mathrm{X}_{2}$ & S & $\mathrm{CF}$ & $n$ & $\mathrm{X}_{2}$ & S & $\mathrm{CF}$ \\
\hline Staphylococci & 61 & $5 \cdot 10$ & 0.31 & 2.05 & 12 & - & - & - & 12 & - & - & - \\
\hline Enterobacteria & 58 & $6 \cdot 60$ & 0.24 & 1.74 & 12 & $5 \cdot 18$ & 0.19 & 1.55 & 12 & $7 \cdot 59$ & $0 \cdot 15$ & 1.41 \\
\hline Lactobacilli & 54 & $9 \cdot 14$ & 0.26 & 2.04 & 12 & $7 \cdot 51$ & 0.15 & 1.41 & 11 & $7 \cdot 71$ & 0.22 & 1.66 \\
\hline Anaerobes & 54 & 9.61 & 0.40 & $2 \cdot 54$ & 12 & 8.04 & 0.17 & 1.49 & 10 & 8.96 & 0.17 & 1.49 \\
\hline Streptococci & 60 & 9.09 & 0.24 & $1 \cdot 24$ & 12 & 7.43 & 0.18 & 1.50 & 10 & $8 \cdot 56$ & 0.09 & $1 \cdot 23$ \\
\hline
\end{tabular}

individuals are distributed among them, and because of this a measure of evenness is also required (Pielou, 1975). In faecal samples from a Wistar rat the diversity of the anaerobes and lactobacilli was high relative to that of the streptococci (Table 12). The low diversity of the streptococci was not only due to the low number of species (Table 3) but also a result of the overwhelming dominance of $S$. salivarius indicated by the low evenness value in Table 12 .

Increasing the complexity of the environment in vitro resulted in increasing diversity and evenness among the lactobacilli (Table 12, also see Table 6 for an example) and anaerobes. For the streptococci, the value of these parameters decreased, as a result of the increasing dominance of $S$. salivarius. In the two-stage cultures, the second stage was always more diverse than the first, presumably because of the less extreme $\mathrm{pH}$ conditions and complex wall growth.

\section{Variation of the microflora in faecal samples and in vitro}

In both the faecal samples and in vitro ecosystems no periodicity was observed in the fluctuations of the various bacterial groups on a time scale of days (as calculated by the methods in Kendall \& Stuart, 1976). Changes in the community structure of the natural and 
artificial ecosystems were statistically random (Siegel, 1956; Sokal \& Rohlf, 1969). The daily fluctuations both in vivo and in vitro were significant and greater than the sampling error as mentioned above. No true steady state with a completely stable community structure was observed in vivo or in vitro, indicating the dynamic nature of the system. The hindgut ecosystem was observed to fluctuate to a greater extent than the in vitro cultures as measured by the coefficient of fluctuation (Whittaker, 1970; Table 13).

\section{DIS CUSSION}

The continuous culture experiments have indicated that it is possible to establish a roughly analogous hindgut flora in vitro on the basis of community composition and structure. Furthermore, the microbial ecosystem that develops in vitro is reminiscent of the original inoculum reflecting the differences in the community composition and structure of the floras of Wistar and Sprague Dawley rats.

Our finding that the development of a multi-species gut flora in vitro required at least a two-stage system may reflect the heterogeneous nature of the selective environment of the gut and its particular hydraulic characteristics. The establishment of a mixed species ecosystem in vitro is a result of the complex nature of the medium, spatial heterogeneity of the environment due to wall growth and the use of cell recycling between the stages. Cell recycling between stages was an essential factor for simulation of a natural gut flora. Recycling served to continuously inoculate the system from the second stage which maintained a high species diversity because of its more favourable $\mathrm{pH}$ environment for most bacterial groups (with the exception of some lactobacilli). In addition, the spatial complexity in stage II due to the growth of bacteria on the vessel wall may also contribute to the persistence of rare species in the system by physically retaining them in the culture.

The importance of recycling is exemplified by the differences in the species diversity of lactobacilli in the two-stage cultures with and without recycling. In both systems, the composition of the lactobacilli community shortly after the initiation of continuous flow (48 h) was similar and composed of primarily L. acidophilus with a minor population of L. lactis. As the cultures developed, this community did not change in the systems without cell recycling (Table 6). However, in the cultures operated with cell recycling, the community developed to the final and more diverse steady-state populations shown in Table 6. Recycling and the $\mathrm{pH}$ regime of stage $\mathrm{II}$, in association with a complex wall growth, maintains the species composition of the faecal inoculum within the culture system until environmental conditions are altered (because of biotic interactions) to a form more suitable for the growth and establishment of a diverse flora. Recycling may also stabilize competitive interactions between species (Weissman \& Benemann, 1979).

It has been shown by a number of workers (Fretner, 1974; Megee et al., 1972) that the ecological mechanisms operating between microbial species are strongly influenced by the environment in which the interaction takes place. The environment in the continuous culture is clearly quite different from that found in the gut. Fretner (1974) has shown that through changes of the environment, one ecological mechanism may replace another without resulting in a dramatic shift in the overall composition of the flora. It is important, therefore, to determine whether the mechanisms maintaining the steady-state community structure in vitro are those most relevant in the natural ecosystem. To this end, we are now comparing the transient response of the in vivo and in vitro ecosystems to environmental perturbations and the similarity of their overall metabolic activity and ability to metabolize various xenobiotics.

We would like to thank Carol Bearne for technical assistance. This work forms part of a research project sponsored by the U.K. Ministry of Agriculture, Fisheries and Food to whom our thanks are due. 


\section{REFERENCES}

Barnes, E. M., Mead, G. C., Impey, C. S. \& Adams, B. W. (1978). Analysis of the avian intestinal flora. In Techniques for the Study of Mixed Populations, pp. 89-105. Edited by D. W. Lovelock \& R. Davies. New York: Academic Press.

BERG, R. D. (1978). Antagonism among the normal anaerobic bacteria of the mouse gastrointestinal tract determined by immunofiuorescence. Applied and Environmental Microbiology 35, 1066-1073.

Cruickshank, R., Duguid, S. P. \& Swain, R. H. A. (1965). Medical Microbiology. Edinburgh \& London: E. \& S. Livingston.

Dolezil, L. \& Kirsop, B. H. (1977). The use of the API Lactobacillus system for the characterization of the pediococci. Journal of Applied Bacteriology 42, 213-217.

Drasar, B. S., Shiner, M. \& McLeod, G. M. (1969). Studies on the intestinal flora. I. Gastroenterology 56, 71-79.

Dubos, R., Schaedler, R. W., Costello, R. \& HoET, P. (1965). Indigenous, normal and autochthonous flora of the gastrointestinal tract. Journal of Experimental Medicine 122, 67-76.

FrETNER, R. (1974). Interactions between mechanisms controlling the intestinal microflora. American Journal of Clinical Nutrition 27, 1409-1416.

Fretner, R. \& Arankl, A. (1973). Patterns of interaction in gnotobiotic mice among bacteria of a synthetic 'normal' intestinal flora. In Germ-free Research. Biological Effect of Gnotobiotic Environments, pp. 429-435. Edited by S. B. Henegan. New York: Academic Press.

FreUnd, J. (1971). Mathematical Statistics. New York: Prentice-Hall.

Gibbons, R. J. \& Kapsimalis, B. (1967). Estimates of the overall rate of growth of the intestinal microflora of hamsters, guinea pigs and mice. Journal of Bacteriology 93, 510-512.

Gorden, H. A. \& Pesti, L. (1972). The gnotobiotic animal as a tool in the study of host microbial relationships. Bacteriological Reviews 35, 390-429.
Holdeman, L. V. \& MOORE, W. E. C. (1975). Anaerobe Laboratory Manual, 3rd edn. Blacksburg, Virginia: Virginia Polytechnic Institute \& State University.

Hungate, R. E. (1969). A roll tube method for cultivation of strict anaerobes. Methods in Microbiology 3B, 117-132.

Kendall, M. \& Stuart, A. (1976). The Advanced Theory of Statistics, vol. 3, Design Analysis and Time Series. London \& High Wycombe: Charles Griffin \& Co.

LEWIS, W. M. (1977). Ecological significance of the shapes of abundance-frequency distributions for coexisting species of phytoplankton. Ecology 58, 850-859.

Megee, R. D., Drake, J. F., Fredrickson, A. G. \& TsuchiyA, H. M. (1972). Studies in intermicrobial symbiosis. Saccharomyces cerevisiae and Lactobacillus casei. Canadian Journal of Microbiology 18, 1733-1742.

NeILl, W. E. (1974). The community matrix and interdependence of the competition coefficients. American Naturalist 108, 399-408.

Pielou, E. C. (1975). Ecological Diversity. New York: John Wiley.

Savage, D. A. (1977). Microbial ecology of the gastrointestinal tract. Annual Review of Microbiology 31, 107-133.

SiEgel, S. (1956). Nonparametric Statistics. New York: McGraw-Hill.

SoKal, R. R. \& RohlF, F. J. (1969). Biometry. New York: W. H. Freeman \& Co.

Weissman, J. C. \& BenEMANN, J. R. (1979). Biomass recycling and species competition in continuous cultures. Biotechnology and Bioengineering 21, 627-648.

WhitTAKeR, R. H. (1970). Communities and Ecosystems. New York: Macmillan Co.

Zubreycki, L. \& Spaulding, E. H. (1954). Studies on the stability of the normal human fecal flora. Journal of Bacteriology 83, 968-974. 